\title{
Investigation into the kinetics of constructed wetland degradation processes as a precursor to biomimetic design
}

\author{
Lara Aylward ${ }^{1,2}$, Uwe Kappelmeyer ${ }^{3 *}$, Ricky Bonner ${ }^{1,2}$, Philipp Hecht ${ }^{4}$ and Craig Sheridan ${ }^{1,2}$ \\ IIndustrial and Mining Water Research Unit (IMWaRU), School of Chemical and Metallurgical Engineering, University of the Witwatersrand, \\ Private Bag X3, PO Wits, Johannesburg, 2050, South Africa \\ ${ }^{2}$ Centre in Water Research and Development (CiWaRD), University of the Witwatersrand, Private Bag X3, PO Wits, Johannesburg, 2050, South Africa \\ ${ }^{3} \mathrm{Helmholtz}$ Centre for Environmental Research GmbH - UFZ, Dept. of Environmental Biotechnology, Permoserstraße 15, 04318, Leipzig, Germany \\ ${ }^{4}$ University of Dresden, Technische Universität Dresden, Institute of Food Technology and Bioprocess Engineering, Bergstraße 120, 01609,
}

Dresden, Germany

\begin{abstract}
In this study, biomimetic principles were incorporated into a kinetic study of a pilot-scale, horizontal subsurface-flow constructed wetland $(6.0 \mathrm{~m} \times 1.0 \mathrm{~m} \times 0.5 \mathrm{~m})$ in Leipzig, Germany. The bed contained glacial gravel $(4-8 \mathrm{~mm})$ planted with Phragmites australis. Construction was completed in October 2013 and experiments commenced in August 2015. During establishment, the system was fed with only municipal tap water $\left(165 \mathrm{~L} \cdot \mathrm{d}^{-1}\right)$. The Phragmites root system had penetrated to the bottom of the wetland within 18 months. To break into the constructed wetland 'black box', the system was divided into a three-dimensional grid of sample ports. Initially, the wetland was physicochemically characterized (prior to addition of nutrients from an external source) in order to quantify the natural, baseline state. Thereafter, an impulse-response tracer test was conducted, using a fluorometer, for continual measurement of uranine concentration. $100 \%$ tracer recovery was achieved. The RTD was multi-modal - indicating by-pass flow - and showed long tailing due to mixing, diffusive effects and dead zones. Kinetic performance was investigated via monitoring total organic carbon and total nitrogen degradation, with a continual feed of artificial domestic wastewater (110 mg. $\left.\cdot \mathrm{L}^{-1} \mathrm{COD}\right) .93 \%$ reduction in TOC and TN was achieved for 5 weeks (11 November - 08 December 2015), despite high inflow loading $\left(69.9 \mathrm{~g} \cdot \mathrm{m}^{-3} \cdot \mathrm{d}^{-1} \mathrm{TOC} ; 28.1 \mathrm{~g} \cdot \mathrm{m}^{-3} \cdot \mathrm{d}^{-1} \mathrm{TN}\right)$ and colder temperatures. There was a general decline in reaction rate and rate constant from late October to early December. The average rates of TOC and TN removal were $65.08 \pm 2.16 \mathrm{~g} \cdot \mathrm{m}^{-3} \cdot \mathrm{d}^{-1}$ and $26.22 \pm 0.68 \mathrm{~g} \cdot \mathrm{m}^{-3} \cdot \mathrm{d}^{-1}$, respectively (Tanks-In-Series model). These results are the first set in a series. Continual observation and repetition of these experiments into long-term operation will deepen understanding of the internal development and performance of constructed wetlands, as is in line with the biomimetic approach, and provide the basis of a framework for improved wetland design.
\end{abstract}

Keywords: constructed wetlands, baseline analysis, hydraulics, kinetics, biomimicry

\section{INTRODUCTION}

South Africa is a water-scarce country - ranked $30^{\text {th }}$ driest globally (Greencape, 2016) - with an annual rainfall of just $50 \%$ of the world average. The country relies predominantly on water from catchments, rivers, wetlands and aquifers (WWF-SA, 2016). Poor water quality has a major negative impact on the livelihood of all South African citizens, as well as the surrounding ecosystem. Water quality in South Africa's natural resources has declined over the past two decades, in some cases to such an extent that the water has become a serious health threat. The primary contributors to the pollution of the country's water resources are:

- Release of raw sewage

- Acid mine drainage (AMD)

- Release of untreated industrial effluent

- Excess nutrients from agricultural runoff

- Poor service delivery from municipal Water Service Authorities

Without urgent attention, South Africa could be faced with a serious water quality crisis (WWF-SA, 2016).

This paper was originally presented at the 2016 Water Institute of Southern Africa (WISA) Biennial Conference, Durban, 15-19 May 2016.

* To whom all correspondence should be addressed.

푱 49341235 1679; e-mail: uwe.kappelmeyer@ufz.de

Received 6 March 2017; accepted in revised form 6 October 2017
South Africa's water resources are governed by the Water Services Act of 1997 (RSA, 1997) and the National Water Act of 1998 (RSA, 1998). In line with the requirements of the two water acts and Government's National Development Plan (NDP), the South African Department of Water and Sanitation (DWS) issued the National Water Resource Strategy 2 (NWRS2). The NWRS2 covers security of water supply, managing environmental degradation and curbing pollution of water resources (DWS, 2013). The DWS, in conjunction with the South African National Biodiversity Institute (SANBI), has proposed a $19^{\text {th }}$ Strategic Integrated Project (SIP) which will use the 'Investment in Ecological Infrastructure (IEI)' model to find joint ecological and engineering solutions to South Africa's water treatment challenges (SANBI, 2014). As South Africa works towards developing its ecological infrastructure, the opportunity arises to move from centralized to decentralized water and wastewater treatment facilities, examples of which include point-of-use household technologies, rainwater harvesting installations, grey-water green roofs and water recycling and reclamation systems (Greencape, 2016).

Constructed wetlands (CWs) are engineered systems, designed to utilize the soil, vegetative and microbial processes of natural wetlands in the treatment of wastewater of different origins, including domestic and municipal sewage, industrial and agricultural wastewater, landfill leachate, AMD, stormwater run-off and mining wastewater (Reed, 1993; Vymazal, 
2005). CWs typically consist of a soil-, gravel- or sand-filled bed planted with various types of macrophyte (most commonly Phragmites australis) (Brix, 1994). Table 1 summarizes the primary contaminants and their mechanisms of removal from CW systems (Vymazal, 2005).

In the past, CWs have most often been used as polishing systems following the primary and secondary water treatment stages (Brix, 1994), but have more recently been identified as a viable, green technology solution to water management in the following areas:

- Regulation of water supply

- Drought alleviation

- Regulation of water quality (particularly for biological and temperature control) (Greencape, 2016)

Biomimicry is defined as 'the practice of learning from and then emulating nature's genius to solve human problems and create more sustainable solutions' (Biomimicrysa, 2015). Throughout the process of evolution, living organisms have survived and adapted to changing conditions in such a way as to ensure continual access to water. For this reason, natural ecosystems and their inhabitants provide many examples of successful water purification processes (Dama-Fakir et al., 2015). For example:

- The ability of the Namibian Fog Beetle to capture water from the air (Kenny et al., 2012)

- The ability of 'curly-whirlies' (desert plants of the Namaqualand) to capture fog from the air with modified leaves and stems (Vogel and Müller-Doblies, 2001)

- The action of worms, beetles and micro-organisms in decomposing forest litter into humus, thereby creating a mat for water filtration on the forest floor (the chemical-free Biolytix water filtration system mimics this process) (Kenny et al., 2012)

- The ability of natural wetland ecosystems to filter sediments and nutrients from surface water (Kenny et al., 2012)

Natural wetlands have a number of important functions, namely, water purification, water capture and storage, flow regulation, flood attenuation, shoreline stabilization and protection, carbon sequestration, air quality regulation, temperature regulation and habitats to support biodiversity (Dama-Fakir et al., 2015). Without their variety of vegetation, micro-organisms, aquatic species and wildlife, wetland ecosystems would not support these functions (Kivaisi, 2001).

As the types of wastewater to be treated become more diverse, so the need for more economical, efficient and robust systems to cope with the treatment demands emerges. Biomimetic principles (Benyus, 2017; Todd and Josephson, 1996) could provide valuable tools to inform the design of improved CW systems. Biomimetic CWs are self-contained, ecologically engineered systems in which waste streams are recycled wherever practicable. In addition, they can be a source of nutrient-rich fertilizers and renewable energy and can act as carbon sinks, air quality regulators, temperature regulators and habitats for biodiversity (Dama-Fakir et al., 2015).

There is real scope for CWs to provide a valuable addition to South Africa's ecological infrastructure. They offer all of the advantages of decentralized systems (Greencape, 2016) and, when designed using biomimetic principles, can offer benefits beyond just water remediation. A case in point is the successful prototype in the Langrug informal settlement close to Franschhoek, South Africa (WWF-SA, 2016). Langrug has been converted into an 'eco-machine' (USEPA, 2002; Jted, 2014), which uses biomimicry to address water purification, stormwater and solid waste management, as well as provide potential for revenue generation (WWF-SA, 2016).

Although the use of CWs for wastewater treatment was documented as early as 1904 (Brix, 1994), much of the pioneering literature views CWs as 'black boxes', and understanding of how these systems operate internally is limited (Albertson, 1998; Haberl et al., 2003; Garcia et al., 2010; Rengers et al., 2016). This research focuses on an overall hydraulic characterization of a newly established pilot-scale CW and an in-depth physico-chemical baseline description to act as points of reference. This is followed by 2 months of feeding artificial domestic wastewater into the wetland and continually monitoring the chemical and physical changes. The chemical characterization will provide insight into the kinetics of total carbon and total nitrogen transformation. The analytical procedure involves dividing the $\mathrm{CW}$ into a grid of sample ports: 7 ports down the length of the bed, each of which is divided into 3 depths. The multitude of sampling locations and samples will provide insight into the internal development and operation of the wetland system. This preliminary data is to form the basis of a long-term study into the internal behaviour of CWs, from start-up into steady operation, and will provide the start of a framework to inform improved biomimetic design.

\section{MATERIALS AND METHODS}

\section{Pilot-scale CWs at the Helmholtz Centre for Environmental Research GmbH - UFZ}

The pilot-scale wetlands at the UFZ are planted, horizontal subsurface flow (HSSF) CWs. The system is filled with glacial gravel (particle size 4-8 $\mathrm{mm}$; voidage $36 \%$; bed height $0.50 \mathrm{~m}$ ) and planted with Phragmites australis. A schematic diagram of the wetland is given in Fig. 1. The boundary structure is an approximately rectangular, stainless-steel container $(6 \mathrm{~m}$ length $x 0.70 \mathrm{~m}$ height). One side down the length of the wetland is constructed at $16^{\circ}$ from the vertical, such that the width at the top and base of the container is $1.2 \mathrm{~m}$ and $1.0 \mathrm{~m}$, respectively. Three fully removable, stainless-steel baskets (height $0.7 \mathrm{~m}$; diameter $0.30 \mathrm{~m}$ ) have been inserted into the central flow path. Each basket contains glacial gravel and has been planted with Phragmites australis, just as in the surrounding wetland system. The basket cages have evenly distributed pores of the

\begin{tabular}{|l|l|}
\hline \multicolumn{2}{|c|}{ Primary contaminants and mechanisms of removal from CW systems } \\
\hline Contaminant & Mechanism of removal \\
\hline Organic matter & Aerobic and anaerobic degradation by bacteria attached to plant roots, rhizomes and media surfaces \\
\hline Suspended solids & Filtration and sedimentation \\
\hline Nitrogen (ammonia or nitrate) & Nitrification/denitrification process and adsorption (if soil grain is sufficiently fine) \\
\hline Phosphorus (phosphate) & Ligand exchange reaction in the presence of iron, aluminium or calcium hydrous oxides \\
\hline
\end{tabular}


same diameter as the average gravel particle size to minimize disruptions to the flow of water. The purpose of the baskets is to be able to transport a predominantly undisturbed section of the CW to the laboratory for more detailed analysis.

The wetland is fed by 3 evenly-spaced inlet valves, which are positioned $5 \mathrm{~cm}$ above the base of the container. The discharge is removed via a single, centred outlet valve, also $5 \mathrm{~cm}$ above the wetland base. The flow rate of water into and out of the wetland is regulated via a gear pump (VGS120, Verder Pump, Germany), motor (SEV6324, SEVA Tec, Germany) and frequency controller (DF51-322-025, MOELLER, Germany) and data is logged to allow for continual monitoring of the flow rates. The water level within the wetland is maintained at $0.5 \mathrm{~m}$ by means of a siphon at the wetland outlet. Construction was completed in October 2013. Figure 2a shows a photograph of the wetlands at the UFZ taken in July 2015. The wetland has been dug into the ground, such that the upper rim and $20 \mathrm{~cm}$ of the boundary walls are visible. Figure $2 \mathrm{~b}$ shows a photograph of the middle basket when it was removed from the wetland in September 2015.

\section{Collection of baseline samples}

From October 2013 to July 2015, the wetland was allowed to establish naturally, without any external nutrient source. Municipal tap water was fed into the system during spring, summer and autumn and shut off during the coldest winter months. In order to determine the baseline characteristics of the newly constructed CW, a set of samples, hereafter referred to as baseline samples, were taken before the commencement of any other experiments. The samples were taken from $24 \mathrm{~cm}$ below the gravel surface. Sampling devices, hereafter referred to as samplers, were inserted into the bed at the locations indicated in Fig. 1a, but not at the system outlet (Port 7) where black norprene tubing was connected directly to the discharge valve. The samplers were L-shaped, stainless steel tubes (Fig. 1b), open at both ends, to allow for the easy movement of water. The long end was inserted into the gravel bed and contained several pore-like holes at the base. These holes were too small to allow for gravel to enter the hollow interior. The short end sat above the surface of the gravel bed and contained a single opening. (a)

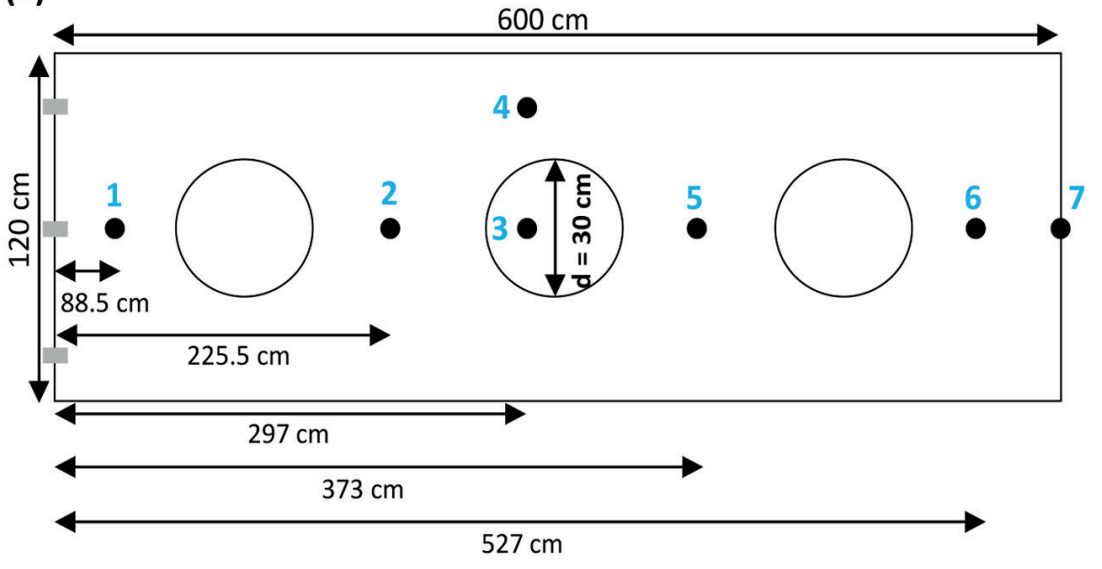

(b)

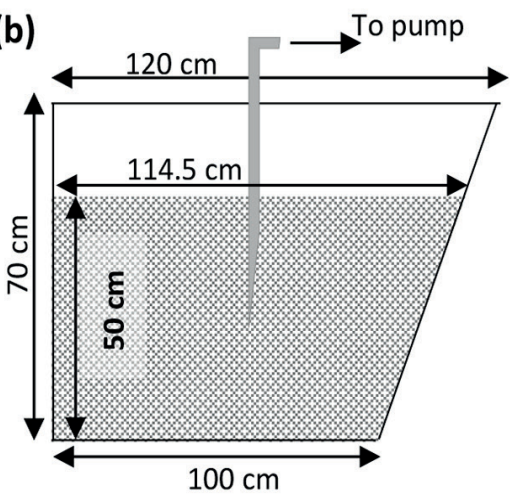

Figure 1

Aerial view of the CW showing (a) sample port and inlet valve locations (outlet valve is Port 7) and (b) cross-sectional view showing one stainless-steel sampling tube
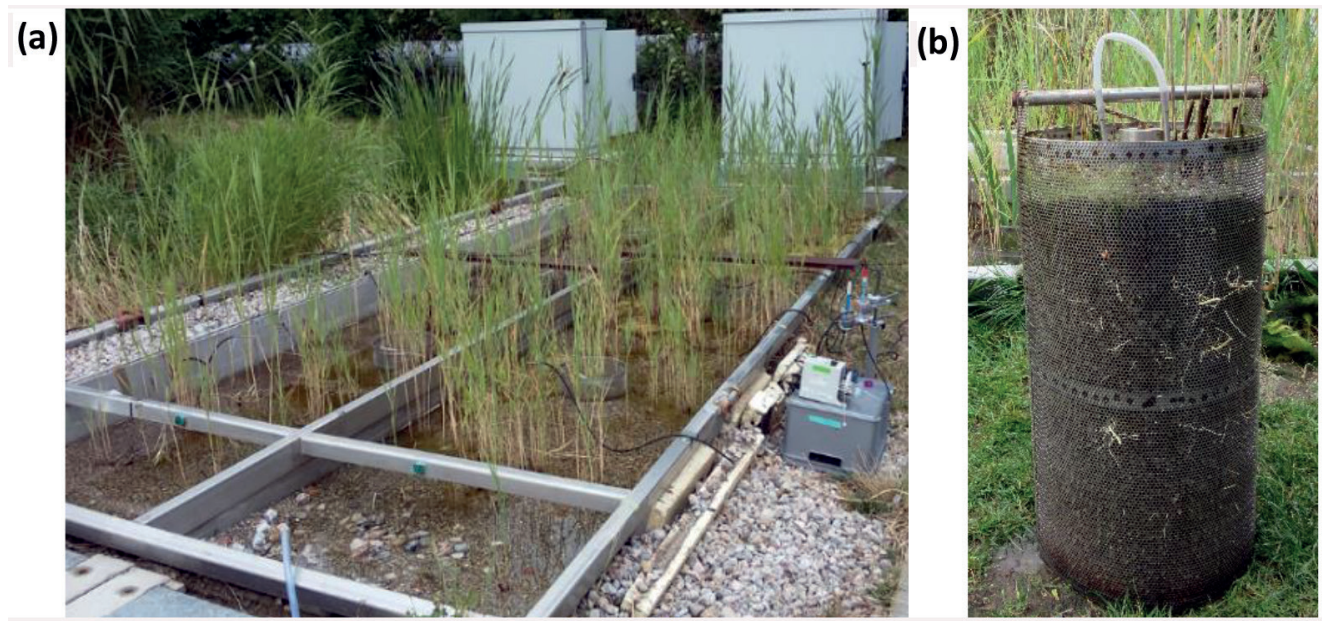

Figure 2

Photographs of (a) the pilot-scale, horizontal subsurface flow CWs at the Helmholtz UFZ (July 2015) and (b) the stainless-steel basket removed from the centre of the wetland showing a well-developed root system (September 2015) 
The short ends of each sampler were connected, one at a time, to a small peristaltic pump (REGLO MS 2/6, ISMATEC $\mathrm{SA}$, Switzerland) via $1.2 \mathrm{~m}$ of black, norprene tubing. Water was pumped continually through flow-through cells for the measurement of dissolved oxygen (DO) (Fibox 3, Presens, Germany), oxidation-reduction (redox) potential (Multi-i340, WTW, Germany), pH (Multi-i340, WTW, Germany) and temperature, after which $20 \mathrm{~mL}$ aliquots were collected, through $0.45 \mu \mathrm{m}$ syringe filters, and submitted to the analytical laboratory for total organic carbon (TOC) and total nitrogen (TN) analysis (Multi N/C 21005, Analytikjena, Germany).

\section{Impulse-response tracer tests}

For the hydraulic investigation, samplers were inserted into the bed at each internal port (Fig. 1a); $24 \mathrm{~cm}$ below the gravel surface. The samplers were connected in pairs. One sampler was the outlet tube, from which water was removed from the wetland, and the second was the return tube. The return tube was fixed to the outlet tube such that the holes at the base of its long end were positioned $6 \mathrm{~cm}$ above those of the outlet tube. Both short ends of the samplers making up each pair were connected to a peristaltic pump (BVP_Z, ISMATEC SA, Switzerland), a stainless-steel flow cell (Schnegg, 2002) and a fluorometer (GGUN-FL, Albillia, Switzerland), using black norprene tubing. This configuration is shown in Fig. 3.

A known mass of uranine fluorescent tracer dye was dissolved in $1 \mathrm{~L}$ of distilled water and injected into the wetland inlet as a single pulse. For the duration of each flow test, water was pumped out of the wetland and through the flow cell, which was connected to the fluorometer, before being returned to the bed at the same location (Fig. 3). The return flow ensured that the total system volume was maintained. The fluorometer was programmed to record data at $10 \mathrm{~s}$ intervals and provided a potential $(\mathrm{mV})$ reading, which was converted to uranine concentration after calibration with feed water from the site (baseline) and a standard uranine solution (70 ppb).

\section{Introduction of artificial wastewater}

An artificial wastewater (AWW) concentrate containing $37.50 \mathrm{~g} \cdot \mathrm{L}^{-1}$ casein peptone, $25.78 \mathrm{~g} \cdot \mathrm{L}^{-1}$ meat extract, $7.03 \mathrm{~g} \cdot \mathrm{L}^{-1}$ urea and $6.56 \mathrm{~g} \cdot \mathrm{L}^{-1}$ dipotassium hydrogen phosphate was prepared, autoclaved and introduced into the CW system via a metering pump (Gamma L GALA1000, ProMinent, Germany). The concentrate was formulated from a published standard based on the average composition of the water released from a treatment plant of Class 2 in Germany; representing between 1 000 and 5000 inhabitant equivalents (FMJC, 2001). A typical analysis of German Class 2 effluent is given in Table 2.

The separate feed water and AWW feed lines were combined into a single pipe and the two fluid streams mixed before

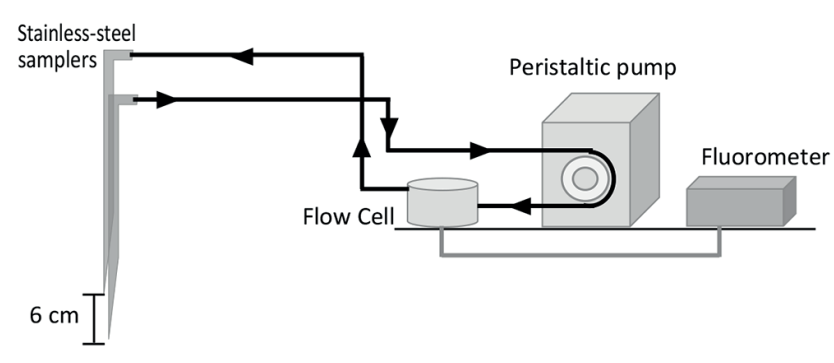

Figure 3

A schematic diagram of the sampling device, pump, flow cell and fluorometer configuration for the tracer flow tests

\begin{tabular}{|c|c|}
\hline \multicolumn{2}{|c|}{$\begin{array}{c}\text { TABLE } 2 \\
\text { Legal limits on environmental discharges for a treatment } \\
\text { plant of Class } 2 \text { in Germany } \\
\text { (based on an inflow of } 300-600 \mathrm{~kg} \cdot \mathrm{d}^{-1} \mathrm{BOD}_{5} \text { ) }\end{array}$} \\
\hline Component & Concentration $\left(\mathrm{mg} \cdot \mathrm{L}^{-1}\right)$ \\
\hline${ }^{\mathrm{a}} \mathrm{COD}$ & 110.0 \\
\hline${ }^{\mathrm{a}} \mathrm{BOD}_{5}$ & 20.0 \\
\hline${ }^{\mathrm{b}} \mathrm{TOC}$ & 22.80 \\
\hline${ }^{\mathrm{b}} \mathrm{TN}$ & 9.14 \\
\hline
\end{tabular}

alegal standard

${ }^{b}$ measured in analytical laboratory (UFZ, Leipzig) from $A W W$ concentrate

entry into the wetland. The individual feed water and AWW loading rates are presented in Table 3. The AWW flow rate was monitored regularly via the 'bucket and stopwatch' method. Weekly sampling commenced 1 week after the introduction of the wastewater and continued for 7 weeks. Samples were taken from $24 \mathrm{~cm}$ below the gravel surface at each sample port, as described previously.

\section{RESULTS AND DISCUSSION}

It was desired that the pilot-scale CWs at the Helmholtz UFZ resemble a natural wetland ecosystem as closely as possible. For this reason, the CWs were allowed to establish naturally, without any external nutrient source, from October 2013 until summer 2015, when these first experiments were scheduled to commence. The results to follow represent the baseline and the very first set of measured data. Due to the complexity and continual internal development of these systems, such experiments will be repeated seasonally and annually into longterm operation of these wetlands. Knowledge and resources from several disciplines in the sciences will be drawn upon to develop a databank of information, to gain a deeper understanding of the operation and continual fluxes within wetland systems and, ultimately, to recommend a methodology and a

\begin{tabular}{|l|c|c|c|c|c|c|}
\hline \multicolumn{7}{|c|}{ TABLE 3 } \\
\hline \multirow{2}{*}{ Week } & \multirow{2}{*}{ Date (2015) } & \multicolumn{2}{|c|}{ HLR $\left(\mathbf{L} \cdot \mathbf{m}^{-\mathbf{2}} \cdot \mathbf{d}^{-\mathbf{1}}\right)$} & \multicolumn{2}{c|}{ HLR $\left(\mathbf{L} \cdot \mathbf{m}^{-\mathbf{3}} \cdot \mathbf{d}^{-\mathbf{1}}\right)$} & \multirow{2}{*}{ Flow ratio } \\
\cline { 3 - 6 } & & Inflow & AWW & Inflow & AWW & (inflow:AWW) \\
\hline 1 & 21 Oct-28 Oct & 76.14 & 0.0982 & 452.4 & 0.583 & 776 \\
\hline 2 & 28 Oct-4 Nov & 76.95 & 0.0899 & 457.2 & 0.534 & 856 \\
\hline $3-7$ & 4 Nov-8 Dec & 20.54 & 0.0806 & 122.0 & 0.479 & 255 \\
\hline
\end{tabular}


set of design parameters for engineering scale-up.

\section{Wetland baseline characterization}

Samples for the baseline characterization were taken in August, September and October of 2015, at which time the wetland was a working system with unknown flux, no additional carbon source and low organic load. The bed temperature, $\mathrm{pH}$, TOC and TN concentration were measured down the length of the wetland and are presented in Table 4.

The $\mathrm{pH}$ of the wetland was found to remain relatively constant (Table 4) and within the physiological range of natural fens and freshwater wetland ecosystems (Kadlec and Wallace, 2009). The TOC and TN concentrations reported in Table 4 give the average natural background levels, below which the measured outlet concentrations are not expected to fall (Kadlec and Knight, 1996). This residual carbon and nitrogen can be accounted for by inherent production of organic substances and carbonaceous material (root exudates), which contribute to the biological oxygen demand (BOD) and decaying plant matter (Bavor et al., 1988; IWA, 2000; Reed, 1993).

The variation in DO and potential within the wetland are plotted in Figs $4 \mathrm{a}$ and b, respectively. For clarity, the DO and redox potential at Sample Port 3, located inside the middle basket (Fig. 1a), has been plotted as individual points. In general, the wetland microcosm within the basket does not show behaviour markedly different to that in the surrounding system, except during October when the DO and potential aligned with the data obtained in August (Fig. 4, ' $\mathrm{x}$ ').

There was a clear consumption of oxygen during August (Fig. 4a, 'o'), accompanied by a lower potential (Fig. 4b, 'o') and a general increase in both wetland DO and potential from August to October. August was the warmest month during the summer of 2015 with high levels of solar radiation. The average daily air temperature and global radiation maxima were measured to be $28.4^{\circ} \mathrm{C}$ and $716 \mathrm{~W} \cdot \mathrm{m}^{-2}$, respectively, at the weather station on-site. These were measured between 11 am and $2 \mathrm{pm}$. The plants were green and their growth rate and level of activity would have been at a maximum under these climatic conditions (Kadlec and Wallace, 2009); hence the greater consumption of oxygen during August.

In the autumn months of September and October, when the average ambient and bed temperatures had begun to decrease (Table 4), there was a reduction in oxygen consumption (Fig. 4a, ' $\nu$ ' $\&$ ' $\square$ ') and a more positive potential (Fig. $4 b$, ' $V$ ' \& ' $\square$ '). Overall, this would be expected because plant activity should have decreased in the autumn period. Also evident is that the oxygen concentrations were closer to the saturation values. In both September and October, approximately $9 \mathrm{mg} \cdot \mathrm{L}^{-1}$ of $\mathrm{O}_{2}$ was measured in the feed water. The water remained oxygen-saturated within the first $100 \mathrm{~cm}$ of the wetland (Fig. 4a, ' $\diamond$ ' \& ' $\square$ '), which would suggest no oxidative processes or exudate transformation up to $100 \mathrm{~cm}$. In September, oxygen was consumed faster within the second $100 \mathrm{~cm}$ of the wetland before reaching a minimum and then increasing until the water was oxygen saturated again close to the outlet (Fig. 4a, ' $\bigcirc$ '). The plant roots are a source of oxygen to the rhizosphere (Kadlec and Wallace, 2009), but it cannot be confirmed that this is the reason for this re-introduction of oxygen into the wetland. The September trend in DO close to the wetland outlet is dissimilar to that in both August and October and, due to the lack of confirmatory experimental data, should be treated with caution. In contrast, the oxygen level decreased progressively down the bed in October (Fig. 4a, ' $\square$ '). This indicated that plant activity decreased down the bed (it was observed that the vegetation density also decreased down the bed) but that the plants were still active although not at the same high level as at the height of the summer.

In summary, Figs $4 \mathrm{a}$ and $\mathrm{b}$ suggest a seasonal influence on
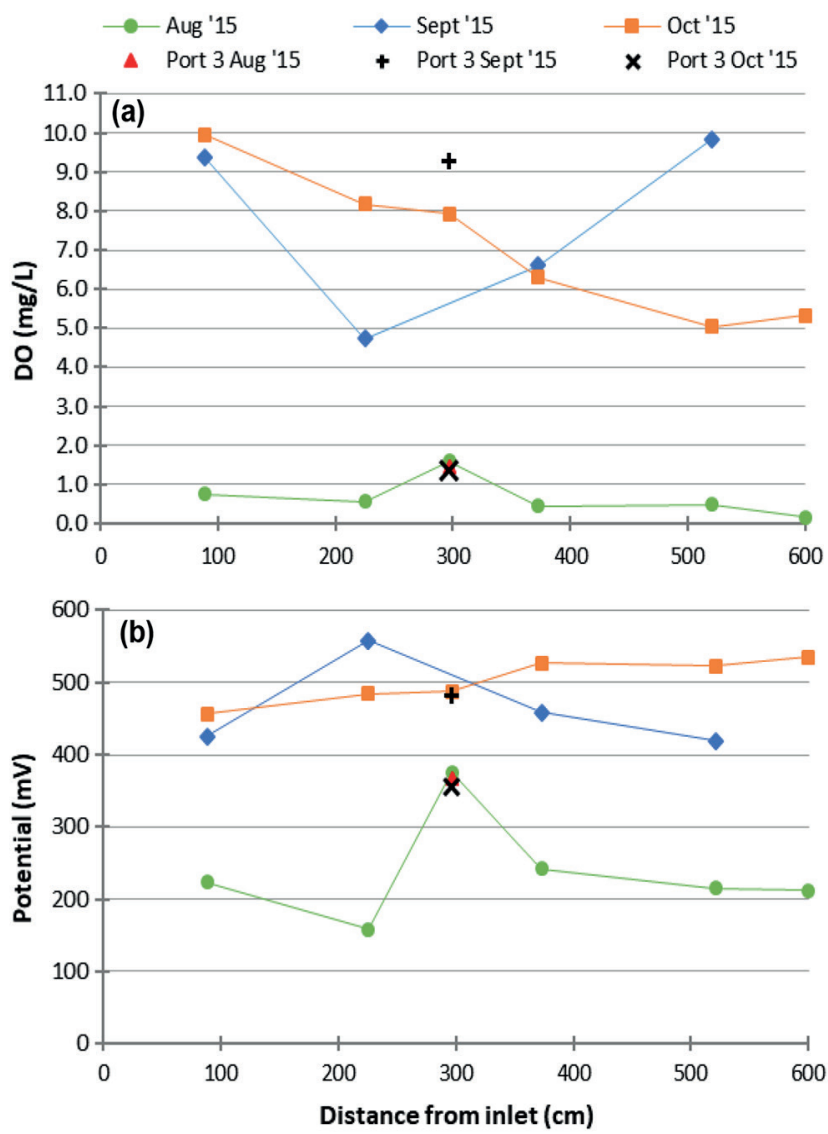

Figure 4

Baseline characterization showing (a) the dissolved oxygen concentration and (b) the oxidation-reduction potential, prior to the introduction of artificial wastewater. Data was obtained from $24 \mathrm{~cm}$ below the gravel bed surface and at increasing distance along the flow path during August, September and October 2015.

TABLE 4

Average bed temperature, $\mathrm{pH}, \mathrm{TOC}$ and TN concentration with the saturated oxygen concentration (fresh water, $760 \mathrm{~mm} \mathrm{Hg}$ ) at the time of the baseline measurements

\begin{tabular}{|l|c|c|c|c|c|}
\hline Period & $\begin{array}{c}\text { Average bed temp } \\
\left({ }^{\circ} \mathrm{C}\right)\end{array}$ & $\begin{array}{c}\text { Saturated oxygen } \\
\left(\mathrm{mg} \cdot \mathrm{L}^{-1}\right)\end{array}$ & $\mathbf{p H}$ & $\mathrm{TOC}\left(\mathrm{mg} \cdot \mathrm{L}^{-1}\right)$ \\
\hline Aug 2015 & $24.1 \pm 2.1$ & 8.5 & $6.85 \pm 0.14$ & $3.11 \pm 0.24$ & $0.54 \pm 0.05$ \\
\hline Sept 2015 & $20.5 \pm 0.3$ & 9.0 & $7.50 \pm 0.21$ & $3.60 \pm 0.30$ & $0.44 \pm 0.02$ \\
\hline Oct 2015 & $16.8 \pm 1.1$ & 9.7 & $7.44 \pm 0.19$ & $2.39 \pm 0.11$ & $0.72 \pm 0.06$ \\
\hline
\end{tabular}


the DO concentration and redox potential, but it cannot be said with certainty whether this is due to changes in the plants or changes in microbial activity in the root zone. However, model experiments have indicated that oxygen input from the plants is dependent on the light intensity and the redox state of the root zone (Kadlec and Wallace, 2009).

\section{Hydraulic characterization}

A gravel HSSF CW can be considered to be a type of packedbed reactor (Sheridan et al., 2014a; Sheridan et al., 2014b; Vymazal and Kröpfelová, 2009). An understanding of wetland hydraulics is a pre-requisite for an investigation into the kinetics of contaminant degradation (Headley and Kadlec, 2007), (Fogler, 2006). The hydraulic investigation of the pilot CW at the UFZ was performed by means of an impulse-response tracer test according to the methodology described by Headley and Kadlec (2007).

Tracer studies should be conducted under laminar, or reversible flow, conditions (Sheridan et al., 2014a; Sheridan et al., 2014b). Before commencing the flow test, the Reynolds number was calculated for the wetland system (Subramanian, 2004) and verified to be less than 10 , which confirmed that flow was well within the laminar region (Miller and Clesceri, 2002).

Subsequent to the completion of the tracer test, the recovery of tracer material was calculated, according to Eq. 1, as the first check on the reliability of the experimental data. Data obtained from a tracer test with a low percentage recovery of material at the system outlet should be treated with caution (Headley and Kadlec, 2007).

$$
R=\frac{v_{0} \int_{0}^{\infty} C(t) d t}{M} \times 100
$$

The method outlined in Fogler (2006), and summarized below, was used to calculate the residence time distribution (RTD) function for the reactor, defined by:

$$
E(t)=\frac{C(t)}{\int_{0}^{\infty} C(t) d t}
$$

$C(t)$ is the time-variant concentration data collected during the flow test and the denominator represents the area under the $C(t)$ curve. The RTD is important because it visually describes dynamic wetland behaviour and fluid flow patterns and is the basis for the calculation of many important hydraulic parameters, one of which is the mean residence time, $t_{m}$, or first moment:

$$
\bar{t}_{m}=\int_{0}^{\infty} t E(t) d t
$$

The mean residence time, $t_{m}$, was compared to the nominal residence time, $\tau$, which is the hypothetical time taken for a pulse of tracer to move from inlet to outlet assuming ideal plug flow:

$$
\tau=\frac{V}{v_{0}}
$$

$V$ is the reactor volume and accounts for the porosity of the packing material, and $v_{0}$ is the system the volumetric flow rate. $t_{m}=\tau$ for a closed, steady-state system with no dead volume.

The variance, $\sigma^{2}$, or second moment of the RTD, is an indication of the spread of the data about the mean and was calculated according to:

$$
\sigma^{2}=\int_{0}^{\infty}\left(t-\bar{t}_{m}\right)^{2} E(t) d t
$$

Owing to the fact that flow was laminar and, thus, completely reversible, the RTD function could be normalized against the mean residence time according to:

$$
\begin{gathered}
\theta=\frac{t}{\bar{t}_{m}} \\
E(\theta)=E(t) \bar{t}_{m}
\end{gathered}
$$

Equations 2, 6 and 7 were employed to produce the normalized RTD function for the reactor outlet in Fig. 5. The shape of the RTD in Fig. 5 suggests that that this system displays behaviour intermediate between plug flow and complete mixing (Headley and Kadlec, 2007). There are two main features in Fig. 5. Firstly, the distribution is multi-modal. There are two distinct peaks prior to $t=t_{m}(\theta=1.0)$. This is typical of a reactor in which there is channelling or by-pass and dead zones (Headley and Kadlec, 2007). The small peaks after $t=t_{m}$ $(\theta=1.0)$ could indicate hold-up in densely vegetated areas or possibly adsorption and desorption of the tracer material onto the gravel (Headley and Kadlec, 2007; Smart and Laidlaw, 1977). Secondly, there is long tailing evident. This can be the result of mixing between the pore spaces, diffusion between regions of faster and slower flow and, again, dead zones (Fogler, 2006).

Various hydraulic parameters, calculated from Eqs 1, 3, 4, 5 and the RTD, are summarized in Table 5. The mean residence time, or time taken for the bulk of the injected pulse of uranine to reach the outlet, was 2.89 days. Ninety-nine percent (99\%) of the injected mass of tracer had exited the wetland after 6.54 days. In general, it takes at least 3 retention times for material to be flushed from the system. Making this assumption, it would take an additional 2 days $(2.89 \mathrm{~d} \mathrm{x} 3=8.67 \mathrm{~d})$ for the tail of the RTD curve to reach baseline concentration again.

\section{Contaminant transformation indicators}

Various physicochemical parameters provide information about water quality. DO is essential for aerobic degradation processes. The ammonium ion is a by-product of the decomposition of a wide range of nitrogen-containing organic matter and high levels of $\mathrm{NH}_{4}^{+}$can produce an environment which is toxic to aquatic organisms. A positive redox potential indicates an oxidizing solution and many pollutants require strong oxidants to facilitate their decomposition (Bellingham, 2012). Organic carbon and the chemical oxygen demand (COD) are important water quality indicators (Kadlec and Wallace, 2009), for which maximum allowable limits are commonly published in environmental legislation.

For the purpose of this very first investigation into the behaviour of this CW system, the TOC and TN concentrations were measured. TOC was chosen because it is a more accurate measure of the degradation of carbon in the system, as opposed to COD which is a cumulative measure of all oxidizable components. Similarly, TN, which is the sum parameter of the nitrogen contributions from ammonium $\left(\mathrm{NH}_{4}^{+}\right)$, nitrate $\left(\mathrm{NO}_{3}^{-}\right)$, nitrite $\left(\mathrm{NO}_{2}^{-}\right)$and organic nitrogen, was considered for this preliminary set of results. The next set of experiments will involve more detailed analysis of the species making up these 


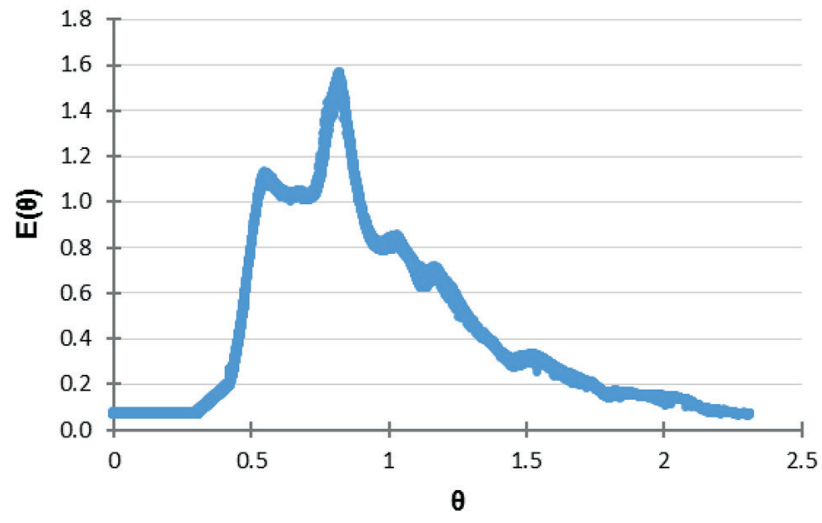

Figure 5

The normalized RTD function for the pilot CW determined from an impulse-response tracer test, with $\tau=2.16 d(\theta=0.78), \operatorname{tm}=2.89 \mathrm{~d}(\theta=1.0)$ and a peak time at maximum concentration of $2.31 d(\theta=0.80)$

TABLE 5

Various hydraulic parameters describing the behaviour of the pilot $\mathrm{CW}$ as determined from the impulse-response tracer test and system RTD

\begin{tabular}{|l|c|}
\hline Hydraulic parameter & Value \\
\hline Mean volumetric flow rate $\left(\mathrm{L} \cdot \mathrm{d}^{-1}\right)$ & 534.7 \\
\hline Reynold's no. $(\mathrm{Re})$ & 0.11 \\
\hline Reactor volume $(\mathrm{L})$ & 1156.2 \\
\hline Mean residence time, $t_{m}(\mathrm{~d})$ & 2.89 \\
\hline Nominal residence time, $\tau(\mathrm{d})$ & 2.16 \\
\hline Variance, $\sigma^{2}\left(\mathrm{~s}^{2}\right)$ & $1.116 \times 10^{10}$ \\
\hline $\begin{array}{l}\text { Peak time at max. concentration } \\
(\text { days after injection) }\end{array}$ & 2.31 \\
\hline$t_{99}(\mathrm{~d})$ & 6.54 \\
\hline Recovery $(\%)$ & 100 \\
\hline
\end{tabular}

sum parameters.

The TOC and TN concentrations at the system outlet over the 7-week experimental period are shown in Figs 6a and $6 \mathrm{~b}$. The inlet and outlet concentration data for Weeks 1 and 2 is plotted as individual points because the system was yet to achieve a state of steady operation. Fig. 6a indicates TOC degradation and Fig. $6 \mathrm{~b}$ shows TN transformation. There is a general decrease in TOC and TN removal from late October to early December, indicated by the increasing outlet TOC and TN concentrations over this period. The change of season and the resultant colder ambient temperatures would have lowered microbial activity and any decomposition of dead bio-matter could have introduced additional nitrogen into the system (Kadlec and Wallace, 2009).

The TOC and TN loading rates, per unit surface area, are given in Table 6 . The calculations were performed on a weekly basis and coinciding with each sampling day. For the purpose of these calculations, it was assumed that the inlet and outlet concentrations of TOC and TN (measured weekly) were the average values for the preceding week. The volumetric flow rate was monitored on a daily basis and the weekly average was calculated. It was further assumed that the system was operating at approximately steady-state $\left(Q_{\text {in }} \approx Q_{\text {out }}\right)$. It is acknowledged
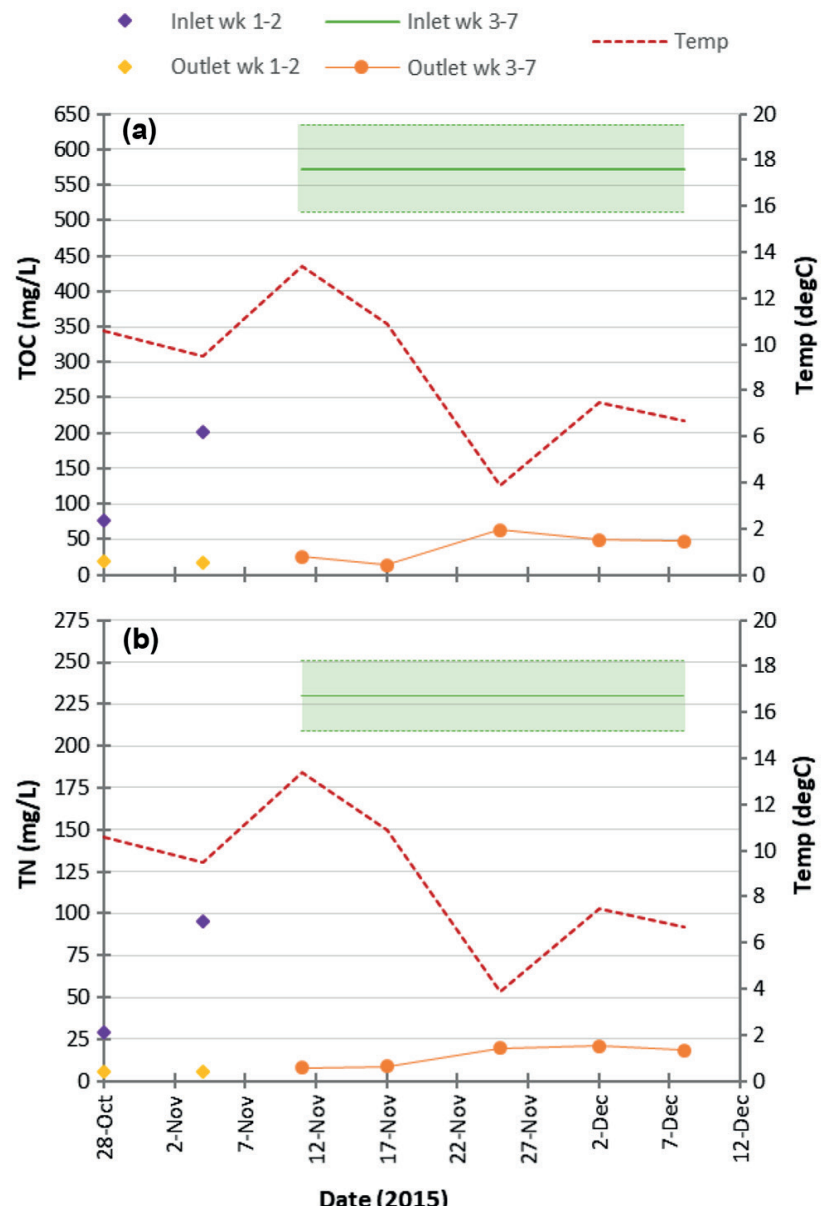

Figure 6

(a) Total organic carbon concentration (avg. inlet [TOC] = $573 \pm 62 \mathrm{mg} \cdot \mathrm{L}^{-1}$; baseline TOC $= \pm 3.0 \mathrm{mg} \cdot \mathrm{L}^{-1}$ ) and $(\mathrm{b})$ total nitrogen concentration (ave. inlet $[T N]=230 \pm 21 \mathrm{mg} \cdot \mathrm{L}^{-1}$; baseline TN

$\left.= \pm 0.57 \mathrm{mg} \cdot \mathrm{L}^{-1}\right)$, as a function of time at the wetland outlet up to 7 weeks after the introduction of artificial wastewater into the system

that this is not the case in reality and increases and decreases in flow rate from inlet to outlet were observed. A decrease in flow was the general trend, unless a large rain event produced an increase in flow from inlet to outlet. However, due to data from the outlet pump being unavailable over the full 7-week duration of the experiment and the fluctuation in flow being in the vicinity of $15 \%$, the steady flow assumption was deemed to be reasonable. In future, it will be beneficial to conduct a more detailed investigation into the fluctuations in the inlet and outlet volumetric flow rates.

When the inflow loads (Table 6) are considered and the inlet concentrations (Fig. 6) are compared to the typical Class 2 German effluent composition (Table 2), it is evident that the system was receiving a noticeably higher load of carbon and nitrogen. The minimum capacity of the metering pump meant that the flow rate of AWW had to be maintained at a higher setting; resulting in a larger ratio of AWW to feed water than initially desired. In addition, the inflow instability experienced over the first 2 weeks reduced the quantity of utilizable data. Due to the limited experimental time available and the 3 -week period required to attain steady operation after adjustments to the pump settings, it was decided to continue with a higher inflow load.

Table 6 shows the percentage of TOC and TN removal, 
calculated on a weekly basis and taking into account the average hydraulic residence time during each week. From Week 3 onwards, once the flow had stabilized, an average of $93.05 \pm 3.09 \%$ removal of TOC and $93.42 \pm 2.42 \%$ removal of $\mathrm{TN}$ were achieved; despite the high inflow loading and the lower temperatures.

Figure $7 \mathrm{~b}$ shows the DO concentration of the outlet stream over the duration of the experiment. Each week, the DO was found to be below $0.75 \mathrm{mg} \cdot \mathrm{L}^{-1}$, which indicates high oxygen consumption when compared to the $11.158 \pm 1.208 \mathrm{mg} \cdot \mathrm{L}^{-1} \mathrm{DO}$ at the wetland inlet. This is thought to be due to the action of micro-organisms in degrading organic carbon (Kadlec and Wallace, 2009). To support this hypothesis, the general trend in TOC concentration as a function of distance along the flow path is also plotted in Fig. 7a and shows that organic carbon is degraded in the first half of the bed. In general, oxygen consumption appears to be higher in the first $300 \mathrm{~cm}$ of the bed, where the largest reduction in TOC is also observed. It is also noted that the standard deviation at each sample port increases with distance down the wetland bed. This spread of data points is most pronounced at the wetland outlet $(600 \mathrm{~cm})$. In general, the DO concentration is greater at the start of the experiment (28 October) and lower towards the end of the sampling campaign (8 December). In the autumn (October/November 2015), the plants could still have been contributing oxygen to the system (Kadlec and Wallace, 2009); hence the higher DO data on 28 October, 11 and 17 November in the sample ports after $300 \mathrm{~cm}$, where TOC degradation had largely ceased. As the experiment proceeded into the beginning of winter (December 2015), oxygen input by the plants should have been much less, but the plants were still observed to be active up until 8 December. The continued activity, even if slower at this time, coupled with reduced oxygen input from the roots, could explain the lower DO data on 2 and 8 December in the sample ports after $300 \mathrm{~cm}$ and the larger spread of data points for these latter sample ports.

The redox potential as a function of time at the wetland outlet is plotted in Fig. 8 and a progressive decrease in potential can be seen over the 7-week experiment. This decrease in potential indicates that the system became more anoxic, as would be expected if oxidative degradation processes were taking place. Oxidative degradation may have produced a number of reduced species, such as nitrate $\left(\mathrm{NO}_{3}^{-}\right)$and nitrite $\left(\mathrm{NO}_{2}^{-}\right)$. The presence of these reduced species would have contributed to the observed decline in redox potential (Kadlec and Wallace, 2009).

\section{Kinetics of contaminant degradation}

For the purposes of this paper, the rates of transformation of TOC and TN (from urea) were considered. The RTD was used to guide the choice of a reactor model to describe the system so that the rate constants for these transformations could be calculated. The tanks-in-series (T-I-S) model, along with a first-order rate law, was chosen for this preliminary investigation. According to the T-I-S model, a packed bed reactor can be described by a number of continuously stirred tank reactors (CSTRs) of equal volume in
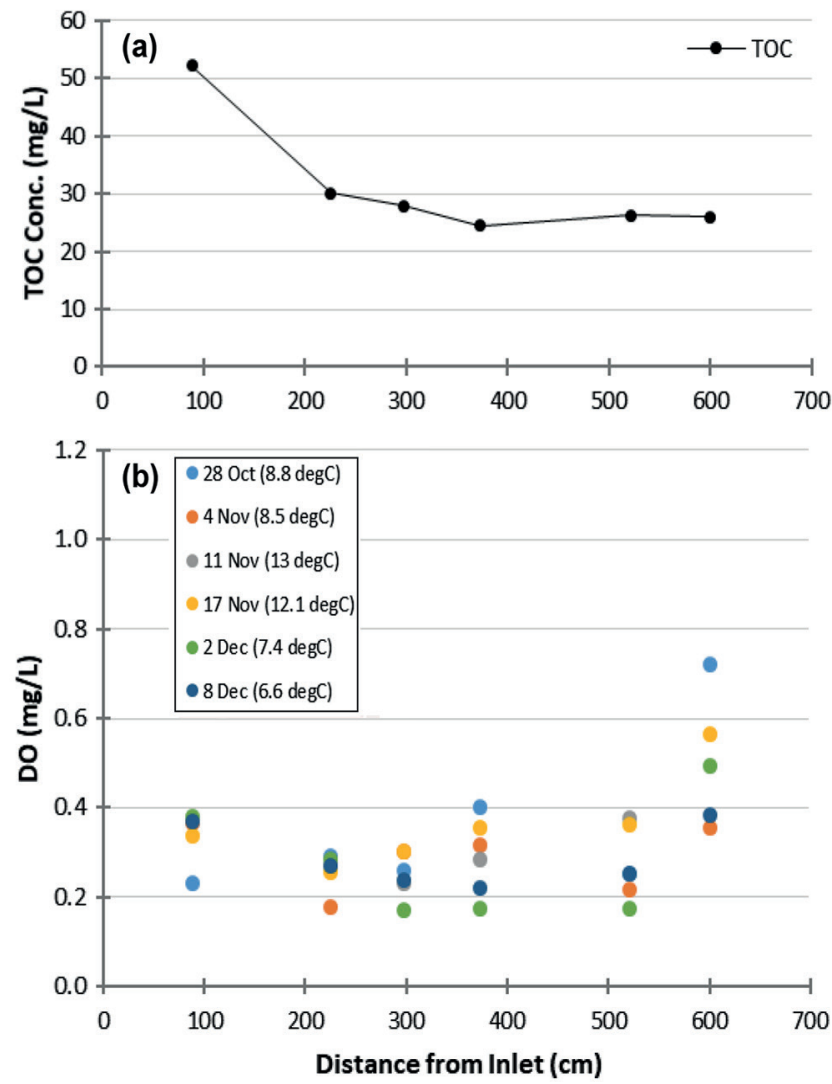

Figure 7

(a) The general trend in TOC concentration (ave. inlet $\left.[T O C]=573 \pm 62 \mathrm{mg} \cdot \mathrm{L}^{-1}\right)$ and $(b)$ the dissolved oxygen concentration at increasing distance from the wetland inlet over the 7-week experimental period (ave. inlet $[D O]=11.158 \pm 1.208 \mathrm{mg} \cdot \mathrm{L}^{-1}$; ave. inlet temp $\left.=10.9 \pm 2.6^{\circ} \mathrm{C}\right)$

\begin{tabular}{|c|c|c|c|c|c|c|c|c|}
\hline \multicolumn{9}{|c|}{$\begin{array}{c}\text { TABLE } 6 \\
\text { Total organic carbon and total nitrogen average weekly hydraulic loading rate and percentage removal }\end{array}$} \\
\hline \multirow{3}{*}{ Week } & \multirow{3}{*}{ aDate (2015) } & \multirow{3}{*}{$\begin{array}{l}\text { Ave. bed } \\
\text { temp. }\left({ }^{\circ} \mathrm{C}\right)\end{array}$} & \multicolumn{3}{|c|}{ TOC } & \multicolumn{3}{|c|}{ TN } \\
\hline & & & \multicolumn{2}{|c|}{$\left.\left.\operatorname{HLR}\left(g \cdot m^{-3} \cdot d^{-1}\right)\right) g / m^{3} \cdot d\right)$} & \multirow{2}{*}{$\%$ removal } & \multicolumn{2}{|c|}{$\operatorname{HLR}\left(g \cdot \mathrm{m}^{-3} \cdot \mathrm{d}^{-1}\right)$} & \multirow{2}{*}{$\%$ removal } \\
\hline & & & Inflow & Outflow & & Inflow & Outflow & \\
\hline 1 & 21 Oct-28 Oct & 8.8 & 34.7 & 8.68 & 75.01 & 13.3 & 2.68 & 79.86 \\
\hline 2 & 28 Oct-04 Nov & 8.5 & 92.0 & 7.54 & 91.81 & 43.5 & 2.73 & 93.71 \\
\hline 3 & 04 Nov-11 Nov & 13.0 & 69.9 & 3.17 & 95.47 & 28.1 & 0.97 & 96.56 \\
\hline 4 & $11 \mathrm{Nov}-17 \mathrm{Nov}$ & 10.6 & 69.9 & 1.67 & 97.62 & 28.1 & 1.09 & 96.12 \\
\hline 5 & 17 Nov-25 Nov & 3.3 & 69.9 & 7.73 & 88.95 & 28.1 & 2.39 & 91.47 \\
\hline 6 & 25 Nov-02 Dec & 7.4 & 69.9 & 5.97 & 91.47 & 28.1 & 2.55 & 90.93 \\
\hline 7 & $02 \mathrm{Dec}-08 \mathrm{Dec}$ & 6.6 & 69.9 & 5.76 & 91.77 & 28.1 & 2.25 & 92.00 \\
\hline
\end{tabular}

${ }^{a} 2^{\text {nd }}$ mentioned date in each row is the day on which samples were taken and analysed 
series. The number of tanks in series, $n$, was calculated by:

$$
n=\frac{\tau^{2}}{\sigma^{2}}
$$

This method requires a constant inflow concentration and volumetric flow rate. The conversion, $X$, of the reacting species was related to the mean residence time and reaction rate constant by:

$$
\begin{aligned}
& X=1-\frac{1}{\left(1+\tau_{i} k\right)^{n}} \\
& \text { where } \tau_{i}=\frac{V}{v_{0} n}
\end{aligned}
$$

where conversion is defined by the quotient of the number of moles of the species reacted to the number of moles of the same species fed into the system. Hence, in terms of concentration:

$$
C_{A}=C_{A 0}(1-X) \text { or } \frac{C_{A}}{C_{A 0}}=(1-X)
$$

Substituting Eq. 11 into Eq. 9 yields:

$$
C_{A}=\frac{C_{A 0}}{\left(1+\tau_{i} k\right)^{n}}
$$

Equation 12 was used to solve for the reaction rate constants (Fogler, 2006).

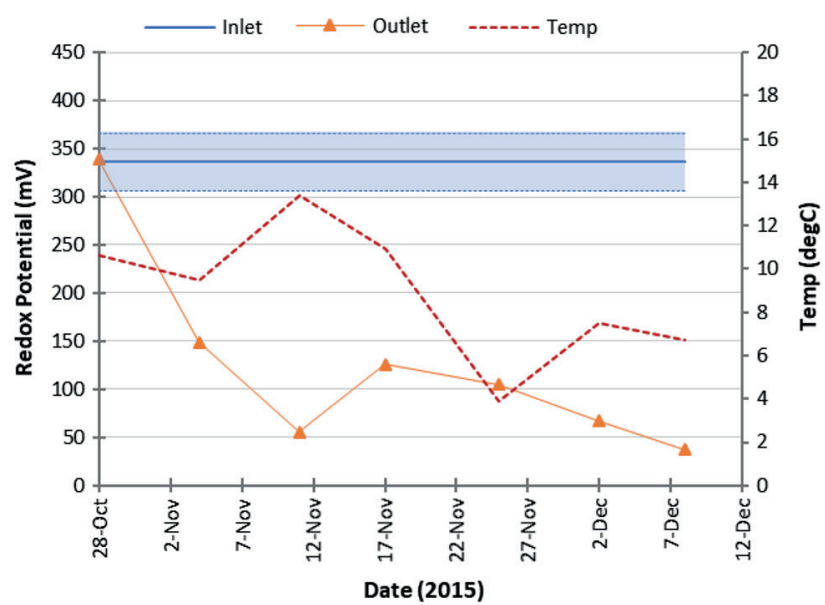

Figure 8

The change in oxidation-reduction potential as a function of time at the wetland outlet up to 7 weeks after the introduction of artificial wastewater into the system (ave. inlet potential $=336.1 \pm 30.1 \mathrm{mV}$ ).
Figure 9 shows the rate constants for the degradation of TOC and the transformation of TN from Week 3 onwards when the system was operating more stably, with the calculated values presented in Table 7. A similar trend of variation in rate constants, with regards to both carbon and nitrogen, can be seen. A certain degree of variation in the rate constants may be expected because TOC and TN are sum parameters and dependent on multiple chemical processes. In addition, the temperature dependence of the rate constant should also be considered. The reaction rate constant of most chemical reactions is directly related to the reaction temperature and increases with an increase in temperature, or vice versa (Atkins and De Paula, 2006). The temperature in the wetland decreased as the weeks progressed from autumn into the beginning of winter (Fig. 9), and this could account for the general decline in the reaction rate constant, particularly beyond the third week of the experiment. As the microorganisms acclimatize to the different types and quantities of nutrients available and plant activity increases significantly with the onset of spring in 2016, it is expected that the rate constants will change. Thus, the values calculated here should be treated as a point of reference.

The rates of TOC and TN removal over the same period (Weeks 3-7) are also presented in Table 7. The rates have been calculated on a weekly basis. It is difficult to compare the rate of TOC degradation with the rate of $\mathrm{TN}$ transformation directly because the wetland was subject to different inlet loading rates (the system received 2.5 times more organic carbon than nitrogen). For direct

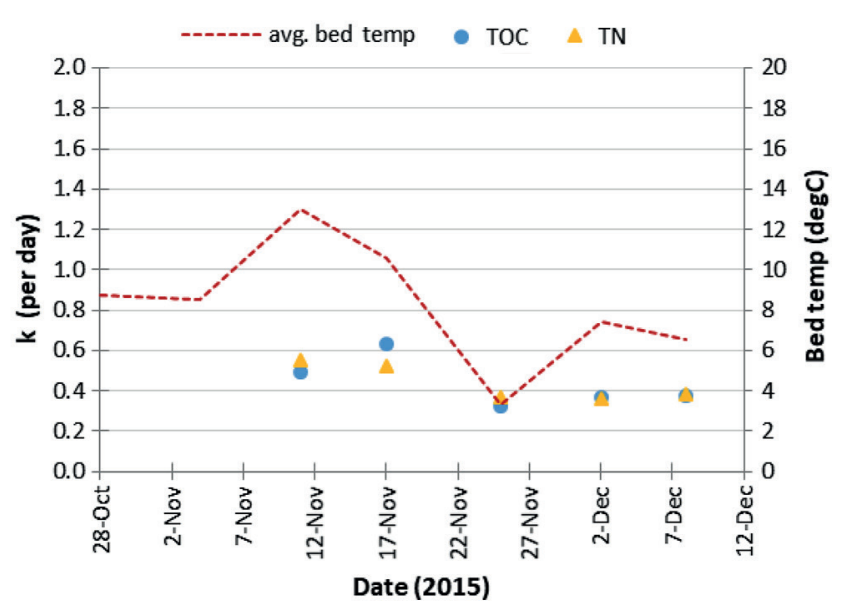

Figure 9

The variability in the rate of decomposition of total organic carbon,

\begin{tabular}{|c|c|c|c|c|c|c|}
\hline Week & aDate (2015) & Ave. bed temp $\left({ }^{\circ} \mathrm{C}\right)$ & $k_{\text {TOC }}\left(\mathbf{d}^{-1}\right)$ & $r_{\text {ТОС }}\left(\mathbf{g} \cdot \mathbf{m}^{-3} \cdot \mathbf{d}^{-1}\right)$ & $k_{\mathrm{TN}}\left(\mathrm{d}^{-1}\right)$ & $r_{\mathrm{TN}}\left(\mathrm{g} \cdot \mathrm{m}^{-3} \cdot \mathrm{d}^{-1}\right)$ \\
\hline 3 & 04 Nov-11 Nov & 13.0 & 0.494 & 66.77 & 0.552 & 27.10 \\
\hline 4 & 11 Nov-17 Nov & 10.6 & 0.633 & 68.27 & 0.526 & 26.98 \\
\hline 5 & 17 Nov-25 Nov & 3.3 & 0.325 & 62.21 & 0.371 & 25.67 \\
\hline 6 & 25 Nov-02 Dec & 7.4 & 0.371 & 63.96 & 0.360 & 25.52 \\
\hline 7 & $02 \mathrm{Dec}-08 \mathrm{Dec}$ & 6.6 & 0.378 & 64.18 & 0.383 & 25.82 \\
\hline
\end{tabular}
$k_{T O C^{\prime}}$ and the rate of transformation of total nitrogen, $k_{T N}$

TABLE 7

Reaction rate constant and rate of removal of total organic carbon, $r_{\text {Tос' }}$ and total nitrogen, $r_{\text {TN }}$ (inlet load: TOC $=69.9 \mathrm{~g} \cdot \mathrm{m}^{-3} \cdot \mathrm{d}^{-1}$ and TN $=28.1 \mathrm{~g} \cdot \mathrm{m}^{-3} \cdot \mathrm{d}^{-1}$ ) 
comparison, the percentage removal is more meaningful (approximately 93\% reduction in both TOC and TN was achieved). The rate of removal is relatively constant, but there is a greater variation in the rate of TOC degradation $\left(=65.08 \pm 2.16 \mathrm{~g} \cdot \mathrm{m}^{-3} \cdot \mathrm{d}^{-1}\right)$ than in the rate of TN transformation $\left(=26.22 \pm 0.68 \mathrm{~g} \cdot \mathrm{m}^{-3} \cdot \mathrm{d}^{-1}\right)$. The temperature dependence of the reaction rate can also be observed. The reaction rate is higher in Weeks 3 and 4, when the temperature was above $10^{\circ} \mathrm{C}$. There was a sudden drop in temperature in Week 5 , accompanied by a drop in the reaction rate. This is more pronounced for TOC.

\section{CONCLUSION}

Through the monitoring of carbon degradation and nitrogen transformation within this wetland system over a period of 7 weeks, good insight was gained into the performance of a newly established CW. A better understanding of the natural state of the wetland (with no external nutrient source), as well as the impact of sampling location and season, was developed. It was observed that the system was capable of high rates of TOC and TN removal; even when the carbon and nitrogen loadings were high and the experimental period spanned the late autumn and early winter months (lower temperatures and reduced plant activity). However, additional treatment steps or extended retention times may be required to ensure that the effluent is compliant with legal discharge limits. The analytical techniques, methodology and findings can act as a useful point of reference for similar research in South Africa; at least qualitatively.

The fields of engineering, microbiology, chemistry and biomimicry should be better merged in the development of a standard methodology. CW construction and establishment should be followed by an initial background, hydraulic and kinetic investigation. Sampling should be from multiple locations throughout the wetland bed, so as to break into the wetland 'black box'. Thereafter, hydraulic and kinetic studies should be repeated into long-term operation; each time beginning with a background physicochemical analysis to act as a point of reference.

These results are the first set in a series. The planned repetition of flow tests and kinetic studies will generate a databank and create a picture of the internal development and performance of CW systems over time. This is in line with the biomimetic approach of relying upon careful observation and an in-depth understanding of the fundamentals governing natural processes in order to improve system design.

\section{ACKNOWLEDGEMENTS}

The authors would like to acknowledge the following people for their significant contribution towards the results presented in this paper:

- Helmholtz Centre for Environmental Research GmbH UFZ, Dept. of Environmental Biotechnology for access to their outdoor wetlands and laboratory facilities.

- Frau Puschendorf (UFZ, Dept. of Environmental Biotechnology) for her assistance with sample analysis.

- Marie Kurz and Christian Schmidt (UFZ, Dept. of Hydrogeology) for their assistance with the fluorometers.

- Golder Associates South Africa

- The South African Water Research Commission

- University of the Witwatersrand Friedel Sellschop Award 2015
- The National Research Foundation (NRF)

- The German Academic Exchange Service (DAAD)

- Water4Crops (an EU initiative)

\section{REFERENCES}

ALBERTSON ML (1998) Constructed wetlands for wastewater treatment: a proposed research program. Wetlands Engineering and River Restoration Conference 1998, 22-27 March 1998, Denver, Colorado. American Society of Civil Engineers. https://doi. org/10.1061/40382(1998)121

ATKINS P and DE PAULA J (2006) Atkins' Physical Chemistry. Oxford University Press, Oxford

BAVOR HJ, ROSER DJ, MCKERSIE SA and BREEN P (1988) Joint study on sewage treatment using shallow lagoon aquatic plant systems. Hawkesbury Agricultural College/CSIRO/Sydney Water Board, Sydney.

BELLINGHAM K (2012) Physicochemical properties of natural Waters. Stevens Water Monitoring Systems Inc., Portland, Oregon.

BENYUS JM (2017) Biomimicry 3.8 Resource Handbook. URL: http:// static.biomimicry.org/wp-content/uploads/2012/02/Biomimicry_ Resource_Handbook_Excerpt.pdf (Accessed 14 October 2017.

BIOMIMICRY SA (2015) Biomimicry 101 Training Manual. Biomimicry Institute of South Africa, Cape Town.

BRIX H (1994) Use of Constructed wetlands in water pollution control: historical development, present status and future perspectives. Water Sci. Technol. 30 209-223.

DAMA-FAKIR P, JANISCH C, O'CONNOR C, OTTO D and WELZ $P$ (2015) Biomimicry and wetlands literature survey. Draft final report for WRC Project No. K5/2096/1. Water Research Commission, Pretoria.

DWA (Department of Water Affairs, South Africa) (2013) National Water Resource Strategy. June 2013 Second Edition. Department of Water Affairs, Pretoria.

FMCJ (Federal Ministry of Justice \& Consumer Protection, Germany) (2001) German Federal Law Gazette (Bundesgesetzblatt): Regulations around Requirements Regarding the Discharge of Wastewater. 2450-2451. Bundesanzeiger Verlagsgesellschaft mbH, Germany.

FOGLER HS (2006 Elements of Chemical Reaction Engineering ( $4^{\text {th }}$ edn). Prentice Hall, Massachusetts.

GARCIA J, ROUSSEAU DPL, MORATÓ J, LESAGE E, MATAMOROS $\mathrm{V}$ and BAYONA JM (2010) Contaminant removal processes in subsurface-flow constructed wetlands: A review. Crit. Rev. Env. Sci. Technol., 40 561-661. https://doi.org/10.1080/10643380802471076

GREENCAPE (2016) Water: Market Intelligence Report 2016. Greencape, Cape Town.

HABERL R, GREGO S, LANGERGRABER G, KADLEC RH, CICALINI A.-R, MARTINS-DIAS S, NOVIAS JM, AUBERT S, GERTH A, THOMAS H and co-authors (2003) Constructed wetlands for the treatment of organic pollutants. J. Soils Sediments 3 109-124. https://doi.org/10.1007/BF02991077

HEADLEY TR and KADLEC RH (2007) Conducting hydraulic tracer studies of constructed wetlands: a practical guide. Ecohydrol. Hydrobiol. 7 269-282. https://doi.org/10.1016/ S1642-3593(07)70110-6

IWA (2000) Constructed Wetlands for Pollution Control: Process, Performance, Design and Operation. International Water Association, London.

JTED (John Todd Ecological Design) (2014) John Todd Ecological Design Eco-Machine Waste Treatment and Remediation Systems. John Todd Ecological Design Inc., Massachusetts.

KADLEC RH and KNIGHT RL (1996) Treatment Wetlands. CRC Press, Boca Raton.

KADLEC RH and WALLACE SD (2009 Treatment Wetlands. CRC Press, New York.

KENNY J, DESHA C, KUMAR A and HARGROVES C (2012) Using biomimicry to inform urban infrastructure design that addresses $21^{\text {st }}$ century needs. $1^{\text {st }}$ International Conference on Urban Sustainability and Resilience, 5-6 November 2012, London.

KIVAISI AK (2001) The potential for constructed wetlands for wastewater treatment and reuse in developing countries - a review. Ecol. 
Eng. 16 545-560. https://doi.org/10.1016/S0925-8574(00)00113-0 MILLER PA and CLESCERI NL (2002) Waste Sites as Biological Reactors: Characterization and Modelling, CRC Press, London.

REED SC (1993) Subsurface Flow Constructed Wetlands for Wastewater Treatment: A Technology Review. USEPA Office of Water,

Washington DC.

RENGERS EE, DA SILVA JB, PAULO PL and JANZEN JG (2016) Hydraulic performance of a modified constructed wetland system through a Cfd based approach. J. Hydro-Environ. Res. 12 91-104.

RSA (Republic of South Africa) (1997) Water Services Act. Act No. 108 of 1997. Government Gazette No. 18522. Government Printer, Cape Town.

RSA (Republic of South Africa) (1998) National Water Act. Act No. 36 of 1998. Government Gazette No. 19182. Government Printer, Cape Town.

SANBI (2014) Investing in ecological infrastructure: the practice and the payoff for water security. URL: http://www.grasslands.org.za/ news/entry/investing-in-ecological-infrastructure-the-practiceand-the-payoff-for-water-security (Accessed 26 July 2015).

SCHNEGG P-A (2002) An inexpensive field fluorometer for hydrogeological tracer tests with three tracers and turbidity measurement. In: Bocanegra E, Hernandez $m$ and Usunoff E (eds) Groundwater and Human Development: IAH Selected Papers on Hydrogeology 6. A.A. Balkema Publishers, Leiden, The Netherlands.

SHERIDAN CM, GLASSER D and HILDEBRANDT D (2014a)

Estimating rate constants of contaminant removal in constructed wetlands treating winery effluent: a comparison of three different methods. Process Saf. Environ. Prot. 92 903-916. https://doi. org/10.1016/j.psep.2013.09.004
SHERIDAN CM, HILDEBRAND D and GLASSER D (2014b) Turning wine (waste) into water: toward technological advances in the use of constructed wetlands for winery effluent treatment. AIChE J. 60 420-431. https://doi.org/10.1002/aic.14297

SMART PL and LAIDLAW IMS (1977) An evaluation of some fluorescent dyes for water tracing. Water Resour. Res. 13 15-33. https://doi. org/10.1029/WR013i001p00015

SUBRAMANIAN RS (2004) Flow through packed beds and fluidized beds. URL: http://www.pdfdrive.com/flow-through-packed-bedsand-fluidized-beds-clarkson-university-e1826488.html (Accessed 21 February 2017).

TODD J and JOSEPHSON B (1996) The design of living technologies for waste treatment. Ecol. Eng. 6 109-136. https://doi. org/10.1016/0925-8574(95)00054-2

USEPA (United States Environmental Protection Agency) (2002) Wastewater Technology Fact Sheet: The Living Machine. United States Environmental Protection Agency, Washington DC.

VOGEL S and MÜLLER-DOBLIES U (2001) Desert geophytes under dew and fog: the 'curly-whirlies' of Namaqualand (South Africa). Flora 206 3-31. https://doi.org/10.1016/j.flora.2010.01.006

VYMAZAL J (2005) Horizontal sub-surface flow and hybrid constructed wetlands systems for wastewater treatment. Ecol. Eng. 25 478-490. https://doi.org/10.1016/j.ecoleng.2005.07.010

VYMAZAL J and KRÖPFELOVÁ L (2009) Removal of organics in constructed wetlands with horizontal subsurface flow: a review of the field experience. Sci. Total Environ. 407 3911-3922. https://oi. org/10.1016/j.scitotenv.2008.08.032

WWF-SA (2016) Water: Facts and Futures - Rethinking South Africa's Water Future. WWF-SA, Cape Town.

\section{APPENDIX}

\section{Abbreviations}

AMD acid mine drainage

AWW artificial wastewater

$\mathrm{BOD}_{5}$ 5-day biological oxygen demand

COD chemical oxygen demand

CSTR continuous stirred tank reactor

CW constructed wetland

DO dissolved oxygen

HSSF horizontal subsurface flow

RTD residence time distribution

T-I-S tanks-in-series model

TN total nitrogen

TOC total organic carbon

\section{Greek characters}

$\sigma \quad$ standard deviation

$\sigma^{2}$ variance

$\tau$ nominal residence time or hydraulic retention time

$\theta$ normalized time

\section{Nomenclature}

$C_{A 0} \quad$ concentration of Species $\mathrm{A}$ in the feed

$C_{\mathrm{A}} \quad$ concentration of Species A at the system outlet

$C(t) \quad$ time variant tracer concentration

$E(t)$ residence time distribution function

$E(\theta)$ normalized residence time distribution function

$k_{\text {TOC }}$ reaction rate constant for the decomposition of TOC

$k_{T N}^{T O C}$ reaction rate constant for the transformation of TN

$M \quad$ mass of tracer injected

$n \quad$ number of tanks in series

$R \quad$ percentage recovery

$t_{m} \quad$ mean residence/retention time

$\stackrel{m}{V} \quad$ system fluid volume

$v_{0} \quad$ system volumetric flow rate

$X \quad$ conversion or extent of reaction 